\title{
Family structure and full vaccination coverage among children aged I2-23 months in West Africa: Analysis of the interaction effects of maternal education
}

\author{
Joshua O. Akinyemi ${ }^{1,2}$, Oluwaseyi D. Somefun ${ }^{1}$ \& Chukwuedozie K. Ajaero ${ }^{3}$ \\ ${ }^{1}$ Demography and Population Studies Programme, Schools of Public Health and Social Sciences, \\ University of the Witwatersrand, Johannesburg, South Africa \\ ${ }^{2}$ Department of Epidemiology and Medical Statistics, College of Medicine, University of Ibadan, \\ Nigeria \\ ${ }^{3}$ Department of Geography, University of Nigeria, Nsukka, Nigeria \\ odunjoshua@gmail.com
}

\begin{abstract}
Childhood vaccination is affected by many maternal socio-economic and family characteristics but these often change over time such that the pattern of relationship needs to be reappraised periodically. In this study, we investigated the influence of family structure and interaction effects of maternal education on full vaccination coverage in the West Africa. Random effects logistic regression was applied to the most recent demographic and health survey data on children aged 12-23 months in six countries. Main explanatory variable was sex of household head and family type. Children living in female-headed households (FHHS) were less likely to be fully vaccinated in five out of six countries [Liberia $(O R=0.77)$, Mali $(O R=0.64)$, Senegal $(O R=0.80)$, Sierra Leone and Togo $(O R=0.85)$ ]. Polygyny was negatively associated with full vaccination in three countries [Liberia $9 O R=0.79)$, Mali $(O R=0.88)$, Togo $(O R=0.80)$ ]. Interaction effects showed that secondary/higher education enhanced better vaccination coverage among children in $\mathrm{FHHs}$ in five countries. Children of single mothers and polygynous women with secondary/higher education recorded higher likelihood of full vaccination. There was a moderate association between family structure and childhood vaccination but the relationship was modified by maternal education which either mitigated the negative influence or amplified the positive effect of family characteristics. Immunization advocacy and awareness programmes may need to target under-five mothers without formal education and those living in female-headed households and polygynous families.
\end{abstract}

Keywords: Child immunization; Vaccination; Household head; Family type; Socio-economic status; West Africa;

\section{Introduction}

Following the adoption of the Millennium Development Goals (MDGs) as a global framework for action on development priorities, public health efforts in the last two decades have focused on improving child survival by stressing the need for full vaccination. Though childhood mortality rates have declined, many countries especially in West Africa did not achieve the MDG 4, which aimed to reduce death among under-five children by three quarter of the 1990 rates (United Nations, 2015). For instance, under-five mortality in Burkina Faso declined from 202 per 1000 live births in 1990 to 89 per 1000 live births in 2015, failing to achieve the MDG target of 67 per 1000 live births (UNICEF, 2015). As a matter of fact, even though several West African countries made progress in childhood mortality reduction, only Senegal achieved the MDG 4 target by 2015 (UNICEF, 20I5).
The global decline in childhood mortality has been substantially attributed to increased coverage of immunization against Vaccine Preventable Diseases (VPD) such as diptheria, hepatitis B, measles, poliomyelitis, tetanus, tuberculosis and yellow fever. For instance, measles death reduced by $74 \%$ between 2000 and 2007 as a result of wider coverage in measles vaccination (Zuehlke, 2009). The 2013 global immunization coverage report indicated that 23 million deaths from diptheria, tetanus, pertusis and measles were prevented (WHO, 20I5a). However, much still need to be done as $29 \%$ of deaths among under-five children are vaccine preventable (Liu et al., 20I5).

In the African region, though there had been an impressive success in childhood vaccination, there is a need to sustain the gains amidst fears of stalled or reversed progress in some countries (Tarantola et al., 2014). Coverage estimates released by WHO in July 
2015 showed that the region recorded $84 \%$ and $77 \%$ for BCG and DPT3 respectively which are lower than the global coverage of $91 \%$ and $86 \%$ (WHO, 2015a). Further review of coverage in African countries showed wide intra-regional variations with West African countries such as Equitorial Guinea, Nigeria, Liberia, and Mali ranking lowest in DPT3 coverage. In 2013, receipt of all eight basic vaccinations varied widely from $25.3 \%$ in Nigeria to $76.4 \%$ in The Gambia (WHO and UNICEF, 20I4).

Responsibility for uptake of childhood vaccinations rests mostly with mothers who are the primary caregivers. Past studies have identified socioeconomic constraints and problems of access to health facilities as some of the contributing factors to poor coverage of childhood vaccination (Tsawe et al., 2015, Tobin-West and Alex-Hart, 20I I). In addition to these, the immediate social systems of the families in which mothers and children live constitute an important factor. The main empirical challenge in this regard is the inconsistent evidence on the relationship between family structure and child health outcomes in Africa. It appears that the relationship depends on the outcome under consideration and the study setting. Further still, the main evidence on the potential association between family structure and childhood immunization in West African subregion dates back to the early 1990s and only considered Niger and Nigeria (Gage et al., 1997). The results showed that there was no relationship between family structure and child immunization in Niger while polygyny was associated with low immunization uptake in Nigeria. Almost two and half decade after, a lot has changed and this calls for new evidence on these critical issues. For instance, the expanded program on immunization has improved tremendously over the years in different countries (Tarantola et al., 2014). Also, the family system in many parts of Africa has undergone transitions with a tendency towards monogamous unions and increase in female headship of households (Scott et al., 2015). To fill this subsisting knowledge gap, this study was conducted to investigate the relationship between family structure and childhood vaccination in Western Africa.

\section{Literature and hypotheses}

Certain individual and household factors are known to be associated with full vaccination coverage in the African region. The individual-level factors include maternal education, marital status, place of child delivery, child's birth order, and maternal knowledge of immunization schedule (Babalola, 201I, Bbaale, 2013, Egondi et al., 20I5, Kawakatsu and Honda, 20I2). Children whose mothers had at least a secondary education have been found to be more likely to be fully vaccinated compared to those of uneducated mothers (Bbaale, 20I3, Brown and Oluwatosin, 2012, Onsomu et al., 2015, Mukungwa, 20I5). Education enhances a mother's knowledge of the benefits and schedule of the different vaccines for children (Fatiregun and Okoro, 20I2, Kawakatsu and Honda, 20I2). In contrast, there are studies in which the effect of maternal education was not statistically significant in the presence of other control variables especially in rural areas (Odusanya et al., 2008).

Utilisation of maternal and child health care services such as antenatal care and skilled delivery at a health facility have been shown to positively influence childhood vaccination (Babalola, 2009, Bondy et al., 2009). This is because such women would have received health education about childhood immunization schedules and are also likely to be given immunization cards before they are discharged after delivery. Possession of child vaccination cards serves the purpose of reminding the mothers about appointments for their children immunizations. (Tsawe et al., 20/5).

The last two decades have witnessed an upsurge of interests in promotion of women empowerment programmes. In response, population-based surveys such as the demographic and health surveys have included questions on these issues. Analysis of these data have also shown that gender equality and decision-making autonomy among women are positively associated with better childhood vaccination coverage (Antai, 2012, Clouston et al., 20I4, Egondi et al., 20I5, Singh et al., 2015, Singh et al., 2013). Although, the effect was often found to be mostly related to educational attainment as statistical significance is eliminated once education and household socio-economic status are controlled. Similar to other child health outcomes, communitylevel autonomy among women was also found to have stronger influence on children vaccination than individual autonomy (Ebot, 20 I4).

Besides individual women characteristics, family or household characteristics play important roles in healthcare decisions. The power relationship between the household head and mother of underfive determines what resources are available for children well-being (Mackay, 2005). Similarly, the social network within the family setting influence different aspect of childcare practices. Therefore, implication of the living arrangement on the success of child health intervention programmes cannot be over-looked. Even though, these programmes may not be able influence family or household structures, they need to be designed to respond favourably to barriers that these social structures may constitute.

The household /familial factors known to be associated with childhood vaccination are socio- 
economic status (proxied by household wealth index), sex of household head, and household/family type. The literature shows that children from rich households have greater chances of vaccination than their poor counterparts (Antai, 2009, Rossi, 2015). Although, immunization is free in most countries, some women from poor households still have problems getting money to take their children to vaccination centres (Adegboye et al., 20I4, Tsawe et al., 20I5). Children in female-headed households $(\mathrm{FHHs})$ are less likely to be fully vaccinated though the explanations for this is unclear and the evidence is limited to few studies (Adegboye et al., 20l4). In contrast, the literature also shows that children from $\mathrm{FHHs}$ have better health outcomes in terms of nutritional status and survival (Doctor, 20II, Gurmu and Etana, 2013, Kumar and Ram, 2013).

The evidence on the relationship between household/family type and childhood vaccination is limited as the most commonly cited relevant study was conducted in the 1990s (Gage et al., 1997). The findings suggest that children from nuclear households have poorer vaccination coverage which was partly attributed to lower household socioeconomic status and low maternal education. Meanwhile, other recent studies showed that children from polygynous families record greater incidence of under-five mortality and were more likely to have poorer nutritional status (Kumar and Ram, 2013, Omariba and Boyle, 2007, Akinyemi et al., 2016). This inconsistency in the effect of family structure on child health outcomes suggests that it is necessary to investigate different outcomes and cover a wider spectrum of country settings.

In the light of the realities described above, this paper revisits the influence of family structure on full vaccination coverage among under-five children in
West Africa. The focus on the sub-region was informed by two reasons. First, West Africa has many countries (e.g. Liberia, Mali, Senegal, Niger, Nigeria and Ghana) with stagnated or decreasing immunization coverage (Tarantola et al., 20l4). The second reason is because the sub-region has the highest prevalence of polygyny in sub-Saharan Africa (Westoff, 2003). Given the massive boost in immunization coverage in the past two decades (WHO and UNICEF, 20I4) and modest changes in household dynamics in sub-Saharan Africa (Ibisomi and De Wet, 20/4), we investigated three hypotheses on the relationship between family structure and childhood vaccination coverage: (i) there is no difference in childhood vaccination coverage between male and female headed households (ii) there is no association between family type and childhood vaccination and (iii) maternal education do not modify the relationship in (i) and (ii) above.

\section{Data sources and methods}

West African countries with Demographic and Health Surveys (DHS) conducted between 2013 and 2014 were selected for this study. The countries and survey years were Liberia (20l3), Mali (20l2-I3), Nigeria (20I3), Senegal (20I2-20I3), Sierra Leone (20/3) and Togo (20/3-I4). This was with a view to reflecting the current status of vaccination coverage. Mass vaccinations are usually conducted from time to time and as a result, current estimates might not be obtained if older surveys were utilised. Figure I shows the full vaccination coverage derived from the most recent DHS in West African countries. 


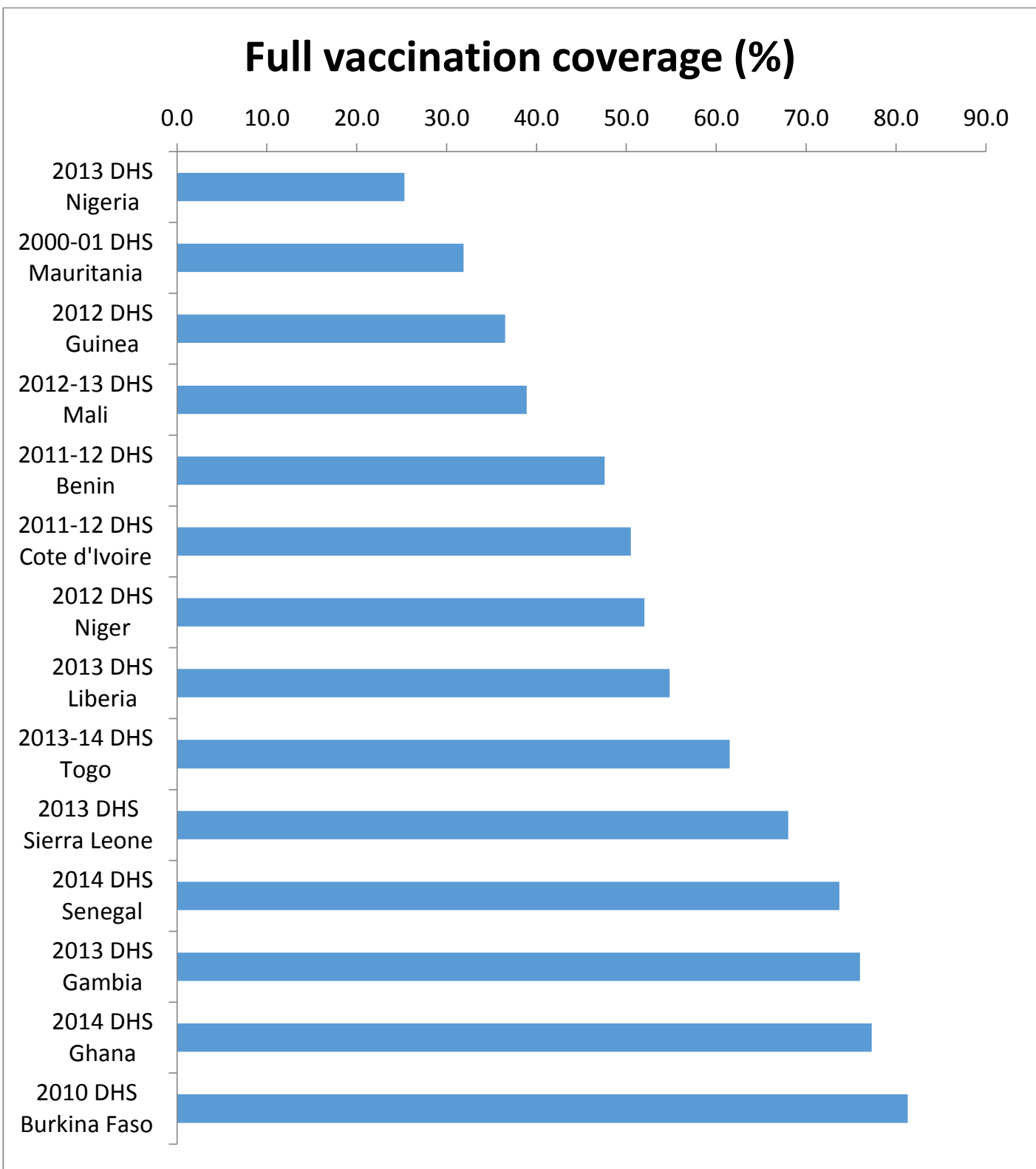

Figure I: Full vaccination coverage in West African countries (based on data extracted from DHS STATcompiler (ICF International, 20I5).

DHSs collect nationally-representative cross-sectional data on maternal and child health and other related topics in several developing countries once in five years. The surveys followed similar standard methodological procedures across different countries (The DHS Program, 2015). Data are usually collected from women aged 15-49 years in households selected using a two-stage cluster sampling technique. Clusters or primary sampling units are defined in terms of enumeration areas from the most recent population census in each country. The survey questionnaire for women covers topics such as fertility, family planning, child health and nutrition, and intimate partner violence. Apart from questions on detail fertility history which are collected from women, data are also collected on childhood vaccination, illnesses and treatment practices. The data analysed for this study includes children aged I2-
23 months extracted from the maternity history records of DHS data for the selected countries.

\section{Dependent and independent variables}

The dependent variable was full vaccination which has two categories [yes-I or no-0]. The World Health Organization (WHO) Expanded Programme on Immunization recommends full vaccination for children. A child is considered fully vaccinated if he or she has received Bacillus Calmette-Guérin (BCG) vaccination against tuberculosis; three doses of vaccine to prevent diphtheria, pertussis, and tetanus (DPT) ; at least three doses of oral polio vaccine (OPV); and one dose of measles vaccine (WHO, $2015 \mathrm{~b}$ ). These vaccines ought to be received during the first year of life. A child aged 12-23 months is deemed to have had full vaccination coverage if he/she has received BCG at birth, DPT and OPV at 6 , 
10 and 14 weeks, and measles vaccine at 9 months (WHO, 20I5b).

The main independent variables were sex of the household head [male or female] and family type categorised as single mother, monogamy and polygyny. Family type was derived from two questions under the marriage section of the DHS women questionnaire. The first question asked about the current marital status of the woman. Possible responses were: "never in union, married, living with partner, widowed, divorced, and separated". The second question which was directed at women who were married or living with partner asked whether their partner had other wives. In deriving the variable for family type, women who were never married, widowed, divorced or separated were classified as single mothers. Those who were married or living with partner and the partner had no other wives were classified to be in monogamy while those whose partners had other wives were categorised as polygyny.

Other control variables were maternal education [categorised as none, primary and secondary/higher], household wealth quintile [categorised as poor, middle, or rich], religion [Christianity, Islam, Traditional/others], parity, birth order, number of antenatal care visits [zero, I-3, 4 and above] and place of child's delivery [home, goverment health facility or private health facility]. The DHS employed principal component analysis to generate wealth index score from selected household items (Rutstein, 2008). For this study, these scores were divided into tertiles [poor, middle, or rich] using the 'xtile' command in Stata 12. The choice of the control variables was informed by evidence from literature as earlier summarized.

\section{Statistical analysis}

Frequencies and percentages were used to summarise the dependent and independent variables. Initial exploratory analyses revealed that the family structure differ between rural and urban children. Consequently, the descriptive analysis conducted in this study was stratified by residence. This helped to better understand the patterns found in the multivariate analysis. To investigate the relationship between family structure and full vaccination coverage, random intercept logistic regression models were fitted in four stages. Model I included female household headship and family type while maternal education was added in model 2 . Household wealth quintile was further included in model 3 and model 4 contained all the independent variables in order to estimate their net effect on full vaccination coverage. The random intercept logit models were employed to adjust for clustering of observations in the same primary sampling units and at the same time account for the random effect of unobserved/unmeasured variables. This helped to ensure that the standard errors of measures of effect (odds ratio) and the confidence interval are not biased. In addition, all analyses were weighted to adjust for differences in sampling probabilities. Stata SE version 12.0 was used for analysis at $5 \%$ significance level.

The four models were based on the following equations:

Model I: $\operatorname{Logitp}_{i j}=\alpha_{j}+\beta_{1} F S_{i j}+v_{j}$

Model 2: Logitp $_{i j}=\alpha_{j}+\beta_{1} F S_{i j}+\beta_{2} M E_{i j}+v_{j}$

Model 3:

$\operatorname{Logitp}_{i j}=\alpha_{j}+\beta_{1} F S_{i j}+\beta_{2} M E_{i j}+\beta_{3} H W_{i j}+v_{j}$

Model 4:

$\operatorname{Logitp}_{i j}=\alpha_{j}+\beta_{1} F S_{i j}+\beta_{2} M E_{i j}+\beta_{3} H W_{i j}+\beta_{4} C V_{i j}+v_{j}$

Where $P_{i j}$ is the probability of full vaccination for child $i$ in community $j .{ }^{\alpha}$ is the average likelihood of full vaccination for children in community $j . v_{k}$ represent the community level random effects which was assumed to follow the Gamma distribution. $\beta_{1} \ldots \beta_{4}$ represent the coefficient for respective variables which are defined as follows:

FS: Family structure (Sex of household head and family type)

ME: maternal education

$H W$ : household wealth quintile

CV: other covariates

For analysis of interaction effects, a term for interaction between family structure and maternal education was added to model 4 . In the results, the coefficients and their confidence interval were exponentiated and interpreted as odds ratio.

\section{Ethical considerations}

This study involved analysis of secondary data extracted from DHS in selected countries. The surveys were approved by national ethics committee in each country and respondents gave informed consent during data collection.

\section{Results}

Family structure of children aged I 2-23 months

The children's living arrangement is presented in Table I. Slightly more than half $(58.4 \%)$ of urban children in Liberia were living in $\mathrm{MHHs}$ compared to $71.3 \%$ in rural areas. Single mother families constituted $32.0 \%$ and $23.6 \%$ in urban and rural areas respectively while polygynous families were $5.4 \%$ and $11.4 \%$ respectively. 
Majority of Malian children lived in MHHs (urban$90.6 \%$, rural-94.1\%). Monogamy was more prevalent in urban $(75.7 \%)$ than rural $(63.4 \%)$ areas while the reverse was the case for polygyny (urban$18.3 \%$, rural- $34.4 \%)$.

In Nigeria, there were more children in $\mathrm{FHHs}$ in urban $(12.5 \%)$ than rural areas (8.8\%). Similarly, monogamous children were more in urban $(74.6 \%)$ than rural (6I.1\%) while the reverse was the case for polygyny (urban-19.9\%, rural-35.0\%).

Table I further shows that more children in urban Senegal $(28.3 \%)$ belonged to $\mathrm{FHHs}$ than rural (I8.1\%). Also, proportion of monogamous children was higher in urban $(73.4 \%)$ while polygyny was more common in rural (30.4\%) compared to urban areas $(20.2 \%)$.

About one-third of urban children in Sierra Leone lived in $\mathrm{FHHs}$ (32.4\%) compared to $22.2 \%$ in rural areas. In terms of family type, $29.0 \%$ in urban and $10.7 \%$ in rural belonged to single mothers while $19.0 \%$ and $32.5 \%$ respectively belonged to polygynous women.

The results also shows that about one-fifth of urban children in Togo were in FHHs (19.8\%) while the proportion in rural areas was $14.3 \%$. Furthermore, $14.7 \%$ (urban) and $33.7 \%$ (rural) lived in polygynous families.

Table I: Family living structure among children aged I2-23 months in West Africa, 20 I3-20 I4

\begin{tabular}{|c|c|c|c|c|c|c|}
\hline \multirow[b]{2}{*}{ Country } & \multicolumn{6}{|l|}{ Urban } \\
\hline & Liberia & Mali & Nigeria & Senegal & Sierra Leone & Togo \\
\hline sample size (n) & 675 & 378 & 2113 & 404 & 561 & 526 \\
\hline \multicolumn{7}{|c|}{ Sex of household head } \\
\hline Male & 58.4 & 90.6 & 87.5 & 71.7 & 67.6 & 80.2 \\
\hline Female & 41.6 & 9.4 & 12.5 & 28.3 & 32.4 & 19.8 \\
\hline \multicolumn{7}{|l|}{ Family type } \\
\hline Single mother & 32.0 & 6.0 & 5.5 & 6.4 & 29.0 & 9.1 \\
\hline Monogamy & 62.6 & 75.7 & 74.6 & 73.4 & 52.0 & 76.2 \\
\hline \multirow[t]{2}{*}{ Polygyny } & 5.4 & 18.3 & 19.9 & 20.2 & 19.0 & 14.7 \\
\hline & \multicolumn{6}{|l|}{ Rural } \\
\hline sample size (n) & 597 & 1469 & 3787 & 826 & 1608 & 869 \\
\hline \multicolumn{7}{|c|}{ Sex of household head } \\
\hline Male & 71.3 & 94.1 & 91.2 & 81.9 & 77.8 & 85.7 \\
\hline Female & 28.7 & 5.9 & 8.8 & 18.1 & 22.2 & 14.3 \\
\hline \multicolumn{7}{|l|}{ Family type } \\
\hline Single mother & 23.6 & 2.2 & 3.9 & 3.9 & 10.7 & 7.1 \\
\hline Monogamy & 65.0 & 63.4 & 61.1 & 65.2 & 56.8 & 59.2 \\
\hline Polygyny & 11.4 & 34.4 & 35.0 & 30.4 & 32.5 & 33.7 \\
\hline
\end{tabular}

\section{Family structure and full vaccination coverage}

The overall percentage of children fully vaccinated in individual countries were: Liberia (54.8\%), Mali (38.9\%), Nigeria (25.3\%), Senegal (70.2\%), Sierra Leone (68.0\%) and Togo (61.5\%). Table 2 shows the vaccination status according to family structure and residence. In Liberia, $63.9 \%$ and $47.6 \%$ of children from $\mathrm{MHHs}$ in urban and rural areas respecitvely were fully vaccinated compared to $53.6 \%$ (urban) and $53.7 \%$ (rural) in $\mathrm{FHHs}$. The percentage of children with full vaccination was the same for single and monogamous women in urban areas but slighty higher than the rates recorded in rural settings. There was no difference in vaccination coverage between polygynous children in urban (49.0\%) and rural areas (49.0\%).

The results for Mali revealed that vaccination rates were generally higher in urban than rural areas. In $\mathrm{FHHs}, 44.9 \%$ and $26.4 \%$ of children in urban and rural areas respectively were fully vaccinated. The http://aps.journals.ac.za rates were similar across family types in urban areas (single-45.4\%, monogamy-49.2\%, polygyny-42.7\%) while children of single mothers $(22.5 \%)$ had the lowest rates in rural areas.

Nigeria had the widest rural-urban gap in vaccination coverage with $52.3 \%$ (urban) and $29.5 \%$ (rural) in FHHs. In terms of family type, children of single $(47.3 \%)$ and monogamous women $(45.9 \%)$ had higher rates than those of polygynous women $(28.1 \%)$ in urban areas. In rural settings, singlehousehold children (31.7\%) were better off than their monogamous (I7.8\%) and polygynous counterparts (10.4\%).

With the highest rates of full vaccination, rural and urban areas in Senegal were quite similar and variations by family structure was minimal. For instance, $71.4 \%$ (urban) and $69.6 \%$ (rural) of children in $\mathrm{MHHs}$ compared to $68.1 \%$ and $72.5 \%$ respectively in $\mathrm{FHHs}$ were fully vaccinated. Vaccination rates were higher for single $(80.2 \%)$ and 
polygynous (7I.4\%) children in rural areas than their urban counterparts.

The pattern of full vaccination rates for Sierra Leonean children showed that there was no difference between $\mathrm{MHH}$ and $\mathrm{FHH}$ in both urban and rural areas. In terms of family type, children of single (urban-65.3\%, rural-75.8\%) and monogamous (urban-70.6\%, rural-65.3\%) women had rates higher than the polygynous (urban-63.5\%, rural-65.9\%).
In Togo, full vaccination rates were higher in urban MHHs (68.2\%) than $\mathrm{FHHs}(58.0 \%)$. Similar pattern was observed for rural but with smaller magnitude (MHHs-59.4\%, FHHs-54.2\%). The disparities across family type was wider in urban (monogamy-69.5\%, polygyny-48.8\%) than rural areas (monogamy $60.5 \%$, polygyny-55.3\%).

Table 2: Pattern of full vaccination according to family structure and residence in West Africa

\begin{tabular}{|l|l|l|l|l|l|l|}
\hline & \multicolumn{5}{|l|}{ Household head } & Family type \\
\hline Country & Residence & Male & Female & Single & Monogamy & Polygyny \\
\hline Liberia & Urban & 63.9 & 53.6 & 60.2 & 60.2 & 49.9 \\
\hline & Rural & 47.6 & 53.7 & 52.6 & 48.1 & 49.7 \\
\hline Mali & Urban & 48 & 44.9 & 45.4 & 49.2 & 42.7 \\
\hline & Rural & 37.3 & 26.4 & 22.5 & 38.5 & 33.3 \\
\hline Nigeria & Urban & 41.1 & 52.3 & 47.3 & 45.9 & 28.1 \\
\hline & Rural & 14.4 & 29.5 & 31.7 & 17.8 & 10.4 \\
\hline Senegal & Urban & 71.4 & 68.1 & 74.9 & 72.8 & 60.6 \\
\hline & Rural & 69.6 & 72.5 & 80.2 & 68.9 & 71.4 \\
\hline Sierra Leone & Urban & 66.8 & 63.3 & 66.1 & 65.3 & 65.9 \\
\hline & Rural & 69.1 & 68.0 & 75.8 & 70.6 & 63.5 \\
\hline Togo & Urban & 68.2 & 58.0 & 65.9 & 69.5 & 48.8 \\
\hline & Rural & 59.4 & 54.2 & 58.8 & 60.5 & 55.3 \\
\hline
\end{tabular}

\section{Multivariate analysis}

Liberia

For Liberia, model I (Table 3a panel I) shows that children of single mothers were less likely than those of mogomous women to be fully vaccinated $(\mathrm{OR}=0.93, \mathrm{Cl}: 0.72-\mathrm{I} .2 \mathrm{I})$. Following the addition of maternal education (model 2), the odds of full vaccination was further lowered among $\mathrm{FHHs}$ children $\quad(\mathrm{OR}=0.78, \quad \mathrm{Cl}$ : 0.59-I.03) while secondary/higher education $(\mathrm{OR}=2.25 \mathrm{Cl}: \mathrm{I} .69-3.0 \mathrm{I})$ was positively associated with the outcome. Further controls for household wealth quintile and selected maternal health care utilisation variables had little effect on the family structure variables. Specifically, model 4 revealed that neither sex of household head nor family type was significantly associated with full vaccination. Secondary/higher maternal education was positively associated with vaccination $(O R=1.69$, Cl: I.I5-2.49).

Mali

Results on association between family structure and full vaccination among Malian children are presented in Table 3a panel 2. Model I shows that children in $\mathrm{FHHs}$ were less likely to be fully vaccinated $(\mathrm{OR}=0.5 \mathrm{I}, \mathrm{Cl}: 0.32-0.80)$. The same pattern was observed for children of single mothers and polygynous compared to monogamous women. Addition of controls for maternal education (model 2) and household wealth quintile (model 3 ) did not alter the odds ratios for $\mathrm{FHHs}$ and family types in any substantial manner. Model 4 showed that children of single mothers $(\mathrm{OR}=0.50, \mathrm{Cl}: 0.25-\mathrm{I} .0 \mathrm{I})$ and polygynous women $(\mathrm{OR}=0.88, \mathrm{Cl}: 0.68-\mathrm{I} .13)$ were less likely to be fully vaccinated.

Table 3a: Adjusted odds ratio for full vaccination among children aged I2-23 months in Liberia and Mali

\begin{tabular}{|l|l|l|l|l|}
\hline & \multicolumn{4}{|c|}{ Liberia } \\
\hline Variables & Model I & Model 2 & Model 3 & Model 4 \\
\hline & AOR (95\% Cl) & AOR $(95 \% ~ C l)$ & AOR (95\% Cl) & AOR (95\% Cl) \\
\hline Female HH vs Male HH & $0.93(0.72-I .2 \mathrm{I})$ & $0.78(0.59-\mathrm{I} .03)$ & $0.74(0.56-0.98 *$ & $0.77(0.58-\mathrm{I} .04)$ \\
\hline Family structure & & & & \\
\hline Single mother & $\mathrm{I} .25(0.95-\mathrm{I} .66)$ & $\mathrm{I} .08(0.80-1.46)$ & $\mathrm{I} .05(0.78-1.42)$ & $0.99(0.71-1.38)$ \\
\hline Monogamy & $\mathrm{I} .00$ & $\mathrm{I} .00$ & $\mathrm{I} .00$ & $\mathrm{I} .00$ \\
\hline
\end{tabular}


African Population Studies Vol 3I, No I, (Supp.2), 2017

\begin{tabular}{|c|c|c|c|c|}
\hline Polygyny & $0.99(0.62-\mid .57)$ & $0.93(0.58-1.48)$ & $0.90(0.56-1.44)$ & $0.79(0.48-1.29)$ \\
\hline \multicolumn{5}{|l|}{ Maternal education } \\
\hline Primary vs none & & $0.91(0.7|-| . \mid 8)$ & $0.83(0.62-1.09)$ & $0.74(0.53-1.04)$ \\
\hline Secondary/Higher vs none & & $2.25(I .69-3.0 \mathrm{I})^{*}$ & $1.91(1.35-2.69)^{*}$ & $1.69(1.15-2.49)^{*}$ \\
\hline \multicolumn{5}{|l|}{ Wealth quintile } \\
\hline Poor & & & 1.00 & 1.00 \\
\hline Middle & & & $0.89(0.61-1.30)$ & $0.83(0.56-1.24)$ \\
\hline Rich & & & $1.04(0.68-1.59)$ & $0.83(0.53-I .29)$ \\
\hline \multicolumn{5}{|l|}{ Residence } \\
\hline Urban vs rural & & & $1.38(0.92-2.05)$ & $1.33(0.88-2.00)$ \\
\hline \multicolumn{5}{|l|}{ Community Random effects } \\
\hline Variance (SE) & $0.8869(0.1154)$ & $0.8742(0.1150)$ & $0.8698(0.2654)$ & $0.7964(0.1258)$ \\
\hline ICC (SE) & $0.1929(0.0405)^{*}$ & $0.1885(0.0403)^{*}$ & $0.1869(0.0403)^{*}$ & $0.1610(0.0427)^{*}$ \\
\hline \multicolumn{5}{|l|}{ Model parameters } \\
\hline Log-likelihood & -857.5278 & -839.1096 & -836.45 & -789.35 \\
\hline Wald statistic & 2.54 & 37.35 & 41.47 & 77.17 \\
\hline \multirow[t]{2}{*}{$\mathrm{p}$-value } & 0.4676 & $<0.001$ & $<0.001$ & $<0.001$ \\
\hline & \multicolumn{4}{|c|}{ Mali } \\
\hline Female $\mathrm{HH}$ & $0.5 \mathrm{I}(0.32-0.80)^{*}$ & $0.47(0.29-0.75)^{*}$ & $0.50(0.31-0.79)^{*}$ & $0.64(0.40-1.03)$ \\
\hline \multicolumn{5}{|l|}{ Family structure } \\
\hline Single mother & $0.58(0.29-1.14)$ & $0.43(0.21-0.88)^{*}$ & $0.44(0.22-0.88)^{*}$ & $0.50(0.25-1.0 \mathrm{I})$ \\
\hline Monogamy & 1.00 & 1.00 & 1.00 & 1.00 \\
\hline Polygyny & $0.58(0.46-0.72)^{*}$ & $0.56(0.45-0.69)^{*}$ & $0.62(0.49-0.78) 8$ & $0.88(0.68-I .13)$ \\
\hline \multicolumn{5}{|l|}{ Maternal education } \\
\hline Primary vs none & & $1.67(1.15-2.43)^{*}$ & I.88(I.28-2.76)* & $1.94(1.31-2.88)^{*}$ \\
\hline Secondary/Higher vs none & & I.65(I.13-2.42)* & I.8I(I.2I-2.70)* & $2.15(1.4 \mid-3.29)^{*}$ \\
\hline \multicolumn{5}{|l|}{ Wealth quintile } \\
\hline Poor & & & 1.00 & 1.00 \\
\hline Middle & & & $0.6 \mathrm{I}(0.46-0.8 \mathrm{I})^{*}$ & $0.96(0.70-1.32)$ \\
\hline Rich & & & $0.88(0.65-1.17)^{*}$ & $1.28(0.91-1.79)$ \\
\hline \multicolumn{5}{|l|}{ Residence } \\
\hline Urban vs rural & & & $0.97(0.63-1.49)$ & $1.02(0.67-I .56)$ \\
\hline \multicolumn{5}{|l|}{ Community Random effects } \\
\hline Variance (SE) & $1.0137(0.0962)$ & $1.0301(0.0978)$ & $1.0235(0.0969)$ & $0.9194(0.0976)$ \\
\hline ICC (SE) & $0.2380(0.0344)^{*}$ & $0.2439(0.0350)^{*}$ & $0.2415(0.0347)^{*}$ & $0.2012(0.0345)^{*}$ \\
\hline \multicolumn{5}{|l|}{ Model parameters } \\
\hline Log-likelihood & -1197.5758 & -1191.0446 & -1184.8085 & -1108.222 \\
\hline Wald statistic & 35.61 & 47.67 & 59.51 & 119.19 \\
\hline $\mathrm{p}$-value & $<0.001$ & $<0.001$ & $<0.001$ & $<0.001$ \\
\hline
\end{tabular}

* $\mathrm{p}<0.05$

\section{Nigeria}

Model I (Table 3b panel I) shows that Nigerian children from $\mathrm{FHHs}(\mathrm{OR}=\mathrm{I} .2 \mathrm{I}, \mathrm{Cl}$ : 0.94-I.57) had higher likelihood of being fully vaccinated while polygynous children $(\mathrm{OR}=0.49, \mathrm{Cl}: 0.39-0.60)$ were less than their monogamous counterparts. Despite controlling for maternal education (model 2) and household wealth quintile (model 3 ), the direction of effect remained the same though with slightly lower magnitude. Model 4 shows that children in $\mathrm{FHHs}$ are more likely to be fully vaccinated $(\mathrm{OR}=1.23, \mathrm{Cl}$ : 0.96-I.57). Family type did not have any association with full vaccination. However, secondary/higher maternal education was positively associated with the outcome.

http://aps.journals.ac.za

\section{Senegal}

Results for Senegal (Table 3b panel 2) showed that $\mathrm{FHHs} \quad(\mathrm{OR}=\mathrm{I} .4 \mathrm{I}, \mathrm{Cl}: \quad \mathrm{I} .00-\mathrm{I} .98)$ and single motherhood $(\mathrm{OR}=2.24, \mathrm{Cl}$ : I.09-4.6I) increased the chances of full childhood vaccination. However, these effects were overturned when maternal education , household wealth quintile, residence and other variables were controlled in model 4 . The model showed that children from $\mathrm{FHHs}$ had lower odds of full vaccination while single motherhood $(O R=I .31$, $\mathrm{Cl}: 0.62-2.74)$ and polygyny (OR=I.47, $\mathrm{Cl}: 1.62-2.04)$ were positively associated with full vaccination though not statistically significant. Rich household wealth quintile remained a predictor of full vaccination $(\mathrm{OR}=3.22, \mathrm{Cl}$ : I.89-5.45). 
Table 3b: Adjusted odds ratio for full vaccination among children aged 12-23 months in Nigeria and Senegal

\begin{tabular}{|c|c|c|c|c|}
\hline & \multicolumn{4}{|c|}{ Nigeria } \\
\hline & Model I & Model 2 & Model 3 & Model 4 \\
\hline & AOR $(95 \% \mathrm{Cl})$ & AOR $(95 \% \mathrm{Cl})$ & AOR $(95 \% \mathrm{Cl})$ & AOR $(95 \% \mathrm{Cl})$ \\
\hline Female $\mathrm{HH}$ vs Male $\mathrm{HH}$ & $1.21(0.94-1.57)$ & $1.22(0.94-1.57)$ & $1.29(1.00-1.68)$ & $1.23(0.96-1.57)$ \\
\hline \multicolumn{5}{|l|}{ Family structure } \\
\hline Single mother & $0.75(0.52-1.07)$ & $0.69(0.48-0.99)^{*}$ & $0.74(0.52-1.07)$ & I.0I (0.7I-I.43) \\
\hline Monogamy & 1.00 & 1.00 & 1.00 & 1.00 \\
\hline Polygyny & $0.49(0.39-0.60)^{*}$ & $0.49(0.40-0.61)^{*}$ & $0.50(0.4 \mid-0.62)^{*}$ & $1.02(0.83-1.25)$ \\
\hline \multicolumn{5}{|l|}{ Maternal education } \\
\hline Primary vs none & & $0.60(0.48-0.76)^{*}$ & $0.66(0.5 \mid-0.86)^{*}$ & $1.42(1.09-1.85)^{*}$ \\
\hline Secondary/Higher vs none & & I.3I(I.07-I.59)* & I.39(1.08-1.80)* & $2.37(1.82-3.1 \mathrm{I})^{*}$ \\
\hline \multicolumn{5}{|l|}{ Wealth quintile } \\
\hline Poor & & & 1.00 & 1.00 \\
\hline Middle & & & $0.65(0.49-0.84)^{*}$ & $1.54(1.19-2.00)^{*}$ \\
\hline Rich & & & $1.33(0.97-1.80)$ & $2.83(2.15-3.72)^{*}$ \\
\hline \multicolumn{5}{|l|}{ Residence } \\
\hline Urban vs rural & & & $0.63(0.44-0.90)^{*}$ & $1.30(1.03-1.64)^{*}$ \\
\hline \multicolumn{5}{|l|}{ Community Random effects } \\
\hline Variance (SE) & $2.3039(0.1069)$ & $2.2631(0.1064)$ & $2.2104(0.1053)$ & $0.8528(0.0673)$ \\
\hline ICC (SE) & $0.6174(0.0219)^{*}$ & $0.6089(0.0224)^{*}$ & $0.5976(0.0229)^{*}$ & $0.1810(0.0234)^{*}$ \\
\hline \multicolumn{5}{|l|}{ Model parameters } \\
\hline Log-likelihood & -2921.0813 & -2897.746 & -2880.33 & -2298.22 \\
\hline Wald statistic & 48.64 & 94.24 & 128.41 & 982.18 \\
\hline \multirow[t]{2}{*}{ p-value } & $<0.001$ & $<0.001$ & $<0.001$ & $<0.001$ \\
\hline & \multicolumn{4}{|c|}{ Senegal } \\
\hline Female $\mathrm{HH}$ vs Male $\mathrm{HH}$ & $1.4 \mathrm{I}(\mathrm{I} .00-\mathrm{I} .98)^{*}$ & $1.19(0.85-1.67)$ & $0.88(0.62-1.26)$ & $0.80(0.56-I .15)$ \\
\hline \multicolumn{5}{|l|}{ Family structure } \\
\hline Single mother & $2.24(|.09-4.6|)^{*}$ & I.74(0.84-3.59) & $1.52(0.73-3.18)$ & I.3I (0.59-2.57) \\
\hline Monogamy & 1.00 & 1.00 & 1.00 & 1.00 \\
\hline Polygyny & $1.61(1.19-2.17)^{*}$ & $1.58(1.18-2.12)^{*}$ & I.32(0.98-I.78) & $1.16(0.83-1.63)$ \\
\hline \multicolumn{5}{|l|}{ Maternal education } \\
\hline Primary vs none & & I.87(I.36-2.59)* & I.33(0.94-I.89) & $1.19(0.81-1.74)$ \\
\hline Secondary/Higher vs none & & $3.69(2.15-6.33)^{*}$ & $2.19(1.24-3.88)^{*}$ & $\mathrm{I} .44(0.79-2.61)$ \\
\hline \multicolumn{5}{|l|}{ Wealth quintile } \\
\hline Poor & & & 1.00 & 1.00 \\
\hline Middle & & & $2.78(1.86-4.14)^{*}$ & $1.68(1.09-2.57)^{*}$ \\
\hline Rich & & & $3.67(2.24-5.99)^{*}$ & $2.17(1.28-3.69)^{*}$ \\
\hline \multicolumn{5}{|l|}{ Residence } \\
\hline Urban vs rural & & & $0.67(0.40-I . I I)$ & $0.57(0.35-0.93)^{*}$ \\
\hline \multicolumn{5}{|l|}{ Community Random effects } \\
\hline Variance (SE) & $1.0869(0.1314)$ & $0.9674(0.1213)$ & $0.8856(0.1225)$ & $0.7549(0.1286)$ \\
\hline $\mathrm{ICC}(\mathrm{SE})$ & $0.2642(0.0470)^{*}$ & $0.2214(0.0433)^{*}$ & $0.1925(0.0430)^{*}$ & $0.1476(0.0429)^{*}$ \\
\hline \multicolumn{5}{|l|}{ Model parameters } \\
\hline Log-likelihood & -772.8497 & -755.0779 & -731.28 & -668.05 \\
\hline Wald statistic & 19.36 & 55.95 & 101.54 & 137.09 \\
\hline p-value & 0.0002 & $<0.001$ & $<0.001$ & $<0.001$ \\
\hline
\end{tabular}

$* p<0.05$

\section{Sierra Leone}

Results for Sierra Leone are presented in Table 3c panel I. Model I shows that children of single mothers $(\mathrm{OR}=1.95, \mathrm{Cl}: \mathrm{l} .43-2.67)$ and polygynous women were more likely to be fully vaccinated. The magnitude of the relationship was however reduced in the presence of controls for education (model 2) and wealth quintile (model 3 ). Model 4 shows that 
female household headship was associated with lower odds of vaccination. In contrast, single motherhood and secondary/higher maternal education were positively associated with vaccination.

\section{Togo}

In Togo (Table 3c panel 2), model I shows that children in $\mathrm{FHHs}(\mathrm{OR}=\mathrm{I} .06, \mathrm{Cl}: 0.76-\mathrm{I} .49)$ and those of single mothers $(\mathrm{OR}=1.35 \mathrm{Cl}$ : 0.84-2.17) were more likely to be fully vaccinated. Controlling for education and wealth quintile reversed the slight vaccination advantage associated with $\mathrm{FHHs}$ and single motherhood. Model 4 revealed that polygyny $(\mathrm{OR}=0.80, \mathrm{Cl}: 0.59-\mathrm{I} .08)$ slightly reduced the chances of full vaccination in Togolese children while secondary/higher education $(\mathrm{OR}=\mathrm{I} .83, \mathrm{Cl}$ : I.242.7I) increased the odds.

Table 3c: Adjusted odds ratio for full vaccination among children aged I2-23 months in Sierra Leone and Togo

\begin{tabular}{|c|c|c|c|c|}
\hline \multirow[b]{2}{*}{ Variables } & \multicolumn{4}{|c|}{ Sierra Leone } \\
\hline & Model I & Model 2 & Model 3 & Model 4 \\
\hline & AOR $(95 \% \mathrm{Cl})$ & AOR $(95 \% \mathrm{Cl})$ & AOR $(95 \% \mathrm{Cl})$ & AOR $(95 \% \mathrm{Cl})$ \\
\hline Female $\mathrm{HH}$ vs Male $\mathrm{HH}$ & $1.18(0.92-|.5|)$ & I.08(0.84-I.39) & $1.00(0.78-1.29)$ & $0.85(0.66-1.10)$ \\
\hline \multicolumn{5}{|l|}{ Family structure } \\
\hline Single mother & $1.95(1.43-2.67)^{*}$ & $1.43(1.02-1.99) *$ & $1.28(0.92-1.79)$ & $1.19(0.85-1.69)$ \\
\hline Monogamy & 1.00 & 1.00 & 1.00 & 1.00 \\
\hline Polygyny & I.55(I.24-I.94)* & I.49(I.20-।.86)* & I.83(I.33-2.52)* & $0.96(0.75-1.22)$ \\
\hline \multicolumn{5}{|l|}{ Maternal education } \\
\hline Primary vs none & & $1.28(0.95-1.73)$ & I.I40.84-I.55) & $0.98(0.7|-| .34)$ \\
\hline Secondary/Higher vs none & & $2.15(|.59-2.9|)^{*}$ & $1.83(1.33-2.52)^{*}$ & $1.41(0.99-1.98)$ \\
\hline \multicolumn{5}{|l|}{ Wealth quintile } \\
\hline Poor & & & 1.00 & 1.00 \\
\hline Middle & & & I.49(I.14-I.95)* & $0.94(0.7|-| .26)$ \\
\hline Rich & & & I.7I (I.22-2.4I)* & $1.12(0.79-1.59)$ \\
\hline \multicolumn{5}{|l|}{ Residence } \\
\hline Urban vs rural & & & $0.9 \mid(0.59-I .38)$ & $0.67(0.45-0.98)^{*}$ \\
\hline \multicolumn{5}{|l|}{ Community Random effects } \\
\hline Variance (SE) & $1.2419(0.1006)$ & $1.1759(0.0981)$ & $1.1829(0.0984)$ & $0.936 \mid(0.0963)$ \\
\hline $\mathrm{ICC}(\mathrm{SE})$ & $0.3192(0.0352)^{*}$ & $0.2959(0.0348)^{*}$ & $0.2984(0.0348)^{*}$ & $0.2103(0.0342)^{*}$ \\
\hline \multicolumn{5}{|l|}{ Model parameters } \\
\hline Log-likelihood & -1358.2904 & -1345.2736 & -1336.45 & -1242.58 \\
\hline Wald statistic & 36.22 & 63.09 & 80.13 & 177.94 \\
\hline \multirow[t]{2}{*}{$\mathrm{p}$-value } & $<0.001$ & $<0.001$ & $<0.001$ & $<0.001$ \\
\hline & \multicolumn{4}{|c|}{ Togo } \\
\hline Female $\mathrm{HH}$ vs Male $\mathrm{HH}$ & $1.06(0.76-\mathrm{I} .49)$ & $0.78(0.56-1.09)$ & $0.78(0.55-I .09)$ & $0.85(0.59-\mid .2 I)$ \\
\hline \multicolumn{5}{|l|}{ Family structure } \\
\hline Single mother & $1.35(0.84-2.17)$ & $1.01(0.63-1.62)$ & $1.04(0.65-1.68)$ & $0.88(0.53-1.45)$ \\
\hline Monogamy & 1.00 & 1.00 & 1.00 & 1.00 \\
\hline Polygyny & I.04(0.79-I.37) & $0.89(0.69-1.17)$ & $0.88(0.67-I .15)$ & $0.80(0.59-1.08)$ \\
\hline \multicolumn{5}{|l|}{ Maternal education } \\
\hline Primary vs none & & $1.84(1.46-2.32)^{*}$ & $1.62(1.23-2.13)^{*}$ & $1.33(0.97-1.82)$ \\
\hline Secondary/Higher vs none & & $2.91(2.18-3.89)^{*}$ & $2.42(1.72-3.42)^{*}$ & $1.83(1.24-2.71)^{*}$ \\
\hline \multicolumn{5}{|l|}{ Wealth quintile } \\
\hline Poor & & & 1.00 & 1.00 \\
\hline Middle & & & $0.91(0.65-1.27)$ & $0.63(0.44-0.91)^{*}$ \\
\hline Rich & & & $1.82(1.06-3.12)^{*}$ & $0.85(0.48-|.5|)$ \\
\hline \multicolumn{5}{|l|}{ Residence } \\
\hline Urban vs rural & & & $0.76(0.45-I .30)$ & $1.00(0.59-1.68)$ \\
\hline \multicolumn{5}{|l|}{ Community Random effects } \\
\hline Variance (SE) & $0.9612(0.1089)$ & $0.7928(0.1048)$ & $0.8066(0.1063)$ & $0.6966(0.1114)$ \\
\hline $\mathrm{ICC}(\mathrm{SE})$ & $0.2193(0.0388)^{*}$ & $0.1604(0.0356)^{*}$ & $0.1651(0.0363)^{*}$ & $0.1285(0.0358)^{*}$ \\
\hline \multicolumn{5}{|l|}{ Model parameters } \\
\hline Log-likelihood & -930.1454 & -895.3319 & -891.6437 & -832.1224 \\
\hline
\end{tabular}




\begin{tabular}{|l|l|l|l|l|}
\hline Wald statistic & 2.19 & 70.6 & 75.51 & 126.14 \\
\hline$p$-value & 0.5334 & $<0.001$ & $<0.001$ & $<0.001$ \\
\hline
\end{tabular}

* $p<0.05$

\section{Analysis of interaction effects (Table 4)}

Interaction results for Liberia showed that full childhood vaccination was significantly more likely in $\mathrm{FHHs}$ than $\mathrm{MHH}$ if the mother attained at least secondary education. The reverse was the case for lower educational levels. For family type, when the mother has secondary/higher education, full childhood vaccination was higher in single and polygynous than monogamous families.

In Mali, FHH significantly reduced the likelihood of full vaccination in children whose mothers had no formal education. Similar effect was observed at primary and secondary/higher education levels though with smaller magnitude. The odds of full vaccination was also significantly lower in children of single and polygynous mothers with no formal education.

Results for Nigeria showed that there was no significant difference in full vaccination between children in $\mathrm{FHHs}$ and $\mathrm{MHH}$ s at the three educational levels. Single motherhood and polygyny significantly reduced the likelihood of full vaccination when the mother has only primary education. The odds of vaccination was lower among children of polygynous women with secondary education

The odds of full vaccination among Senegalese children was higher in $\mathrm{FHHs}$ than $\mathrm{MHHs}$ and the magnitude of the effect was amplified by secondary/higher education. Similarly, single motherhood and polygyny were positively related to full vaccination and the relationship becane stronger with secondary/higher education.

In Sierra Leone, the odds of full vaccination was higher for children in $\mathrm{FHHs}$ and it increased with educational level. Similar effect was observed for single motherhood. For Togolese children, the positive effect of single motherhood and polygyny on full vaccination also increased with educational level. 
Table 4: Analysis of the effect of interactions between maternal education and family structure on full childhood vaccination in selected West African countries

\begin{tabular}{|c|c|c|c|c|c|c|}
\hline & Liberia & Mali & Nigeria & Senegal & Sierra Leone & Togo \\
\hline $\begin{array}{l}\text { Education and household } \\
\text { headship }\end{array}$ & AOR $(95 \% \mathrm{Cl})$ & AOR $(95 \% \mathrm{Cl})$ & AOR $(95 \% \mathrm{Cl})$ & AOR $(95 \% \mathrm{Cl})$ & AOR $(95 \% \mathrm{Cl})$ & AOR $(95 \% \mathrm{Cl})$ \\
\hline None: FHH vs MHH & $0.96(0.6 I-I .50)$ & $0.38(0.22-0.67)^{*}$ & $1.38(0.57-3.35)$ & $1.95(1.26-3.01)^{*}$ & $1.38(1.01-1.89)^{*}$ & $0.96(0.55-1.67)$ \\
\hline Pry: FHH vs MHH & $0.73(0.46-I .15)$ & $0.86(0.19-3.78)$ & $0.83(0.49-1.42)$ & $1.64(0.69-3.87)$ & $1.97(0.97-3.98)$ & $1.82(1.12-2.95)^{*}$ \\
\hline Secondary+: FHH vs $\mathrm{MHH}$ & $1.59(1.07-2.37)^{*}$ & $0.7 \mathrm{I}(0.2 \mathrm{I}-2.40)$ & $1.02(0.79-1.32)$ & $3.53(1.24-10.09)^{*}$ & $2.74(1.63-4.58)^{*}$ & I.II (0.54-2.78) \\
\hline \multicolumn{7}{|c|}{ Education and family type: None } \\
\hline Single vs Monogamy & $0.80(0.45-I .43)$ & $0.19(0.05-0.78)^{*}$ & $0.50(0.15-I .67)$ & $4.28(1.28-\mid 4.24)^{*}$ & $1.43(0.87-2.36)$ & I.II $(0.46-2.66)$ \\
\hline Polygyny vs Monogamy & $1.02(0.51-2.04)$ & $0.56(0.44-0.7 \mathrm{I})^{*}$ & $0.40(0.26-0.62)$ & $1.8 \mathrm{I}(1.3 \mathrm{I}-2.49)^{*}$ & $1.90(1.48-2.45)^{*}$ & $0.86(0.59-I .24)$ \\
\hline \multicolumn{7}{|l|}{ Primary } \\
\hline Single vs Monogamy & $0.88(0.57-1.35)$ & $0.71(0.19-2.65)$ & $0.28(0.11-0.72)^{*}$ & $1.72(0.45-6.57)$ & $3.11(1.29-7.53)^{*}$ & $\mathrm{I} .43(0.78-2.6 \mathrm{I})$ \\
\hline Polygyny vs Monogamy & $0.66(0.26-1.69)$ & $0.50(0.19-1.26)$ & $0.29(0.19-0.42)^{*}$ & $2.28(0.89-5.87)$ & $1.16(0.59-2.27)$ & $1.57(1.04-2.35)^{*}$ \\
\hline \multicolumn{7}{|l|}{ Secondary/higher } \\
\hline Single vs Monogamy & $2.48(1.6 \mathrm{I}-3.83)^{*}$ & $0.43(0.13-1.42)$ & $0.94(0.66-I .34)$ & $8.17(0.81-82.65)$ & $3.79(2.29-6.28)^{*}$ & $2.67(0.94-7.56)$ \\
\hline Polygyny vs Monogamy & $\mathrm{I} .83(0.64-5.24)$ & $0.79(0.3 \mathrm{I}-2.03)$ & $0.66(0.49-0.89)^{*}$ & $4.09(0.85-19.76)$ & $1.76(0.83-3.73)$ & $2.00(0.85-4.75)$ \\
\hline
\end{tabular}




\section{Discussion}

In view of the importance of household/family setting for child health care practices, this study provides new evidence concerning the influence of household headship, family type and interaction effect of maternal education on coverage of childhood immunization in selected West African countries where progress has been less than optimal. Our results revealed that vaccination coverage is still far from the $\mathrm{WHO}$ goal of $90 \%$ in all the selected countries.

Although not statistically significant, children in female-headed households ( $\mathrm{FHHs}$ ) were less likely to be fully vaccinated in all study countries with the exception of Nigeria where the reverse was the case. Lower odds of full vaccination had earlier been reported in Nigeria based on a pooled analysis of DHS data from 1990 to 2008 (Adegboye et al., 2014). Absence of spouses had been reportedly associated with lower odds of full vaccination in Western Kenya (Calhoun et al., 20I4) while evidence from Zimbabwe showed otherwise (Rossi, 2015). The mechanism behind $\mathrm{FHHs}$ and full vaccination is not clear because it would have been expected that the relationship will be positive considering women as the primary caregiver for children. The results posed questions for further research: for instance, could it be that women in $\mathrm{FHHs}$ were so stigmatised that they were not motivated to take their children for vaccination? Also, could it be that such households have poorer living conditions (Mberu, 2007) that negatively affected children vaccination? Polygyny was shown to be associated with poor vaccination coverage in Liberia, Mali and Togo. Gage et al (1997) had previously shown that the association was explained by socio-economic status and women education. In the present study, the relationship was partly explained such that significant lower odds of full vaccination was observed among children of polygynous women in the three countries. In contrast, polygyny showed a positive effect in Senegal. This is similar to results from India where children from non-nuclear households/families had better vaccination coverage (Kumar and Ram, 2013). The India study however further showed that the relationship was fully explained by socio-economic status once it was included in the multivariate model. But this was not the case in the current study as the positive relationship betwen polygyny and full vaccination remained in the presence of controls for education, household wealth index, rural-urban residence and other variables. Incidentally, Senegal had the highest coverage (Senegal-70.2\%) of full vaccination. Closer scrutiny of the rural-urban distribution of full vaccination coverage in the country shed more light on the interesting positive relationship. It was one of the very few countries where full vaccination in rural areas was almost at par or even greater than urban settings. These pattern clearly demonstrate the immunization success/progress that can be acheived when rural areas are adequately covered. Furthermore, Senegal might be evidence that immunization programmes can be designed and implemented to overcome socio-cultural challenges posed by family structures. Perhaps, other neighbouring countries in the subregion can learn a few lessons from Senegal immunization programme.

Analysis of interaction effects showed that maternal education modified the relationship between household headship, family type and full childhood vaccination across most countries. While low or lack of formal education did not exert any effect on the relationship, secondary/higher education enhanced better vaccination coverage among children in $\mathrm{FHHs}$ in five countries. In like manner, children of single mothers and polygynous women with secondary/higher education recorded higher likelihood of full vaccination. These results revealed two scenarios. First, when mothers have low or no formal education, female household headship, single motherhood and polgyny have negative effect on vaccination coverage. Second, in situations where women have at least secondary education, the negative influence of female household headship, single motherhood and polygyny are either mitigated or totally reversed. The main implications of these results relate to policies and programmes especially the sustainable development goal that seeks to ensure universal effective healthcare coverage by the year 2030. Improvement in female education is an indisputable ingredient for better child health practices and uptake of survival interventions such as immunization. Several studies in diverse settings has demonstrated the key role of maternal education in child health outcomes (Brown and Oluwatosin, 2012, Fatiregun and Okoro, 2012, Onsomu et al., 2015, Vikram et al., 20I2). Educated mothers are better able to access information on immunization and take concerete steps for their children's health and wellbeing irrespective of the prevailing disadvantages that may be associated with female household headship and polygynous family settings.

In the interim, intervention programmes need to devise strategies to ameliorate the negative effect of female household headship, single motherhood, and polygyny on childhood vaccination. $\mathrm{FHHs}$ and single motherhood may operate through lack of social support and logistics to access immunization services. Polygyny on the other hand may operate via perpetuation of unorthodox beliefs and child healthcare practices which discourage women from 
taking their children for vaccination (Adeyemi and Oyewole, 2014). These two potential mechanisms would need different intervention strategies. Poverty alleviation and other social/welfare support programmes might be effective to overcome the disadvantages associated with $\mathrm{FHHs}$ and single motherhood. Massive health education and advocacy that is specific to different socio-cultural contexts in each country could be an effective tool to overcome socio-cultural barriers to childhood vaccination.

One limitation of this study is the fact that some factors related to the macro environment in each country were not included in the analysis. An example is distance to health facility. Such factors may have shed more light on the inter-country variation in the findings. However, the scope of the present analyses was limited to individual and household level characteristics that affect childhood vaccination. Another limitation is the fact that the role of inter-generational relationships was not explored. The presence of mother or father-in-laws may also determine if a child receives vaccination or not. Although, evidence from Ghana suggest that this type of family structure is fast disappearing (Annim et al., 20I3).

Statistical non-significance of the relationship between family structure and full vaccination in most countries is very likely to be a reflection of the sample size of children aged 12-23 months. With larger sample sizes, statistical significance will likely be attained. Irrespective of non-significant p-values, the pattern of results for relationship between family structure and childhood vaccination in four countries (Liberia, Mali, Sierra Leone and Togo) is a matter of public health concern. These limitations do not override the merits and relevance of the information that this study provides. Ultimately, this study presents new evidence on the relationship between the household/family setting and childhood vaccination in West Africa.

\section{Conclusion}

There was a moderate association between family structure and childhood vaccination and the relationship was modified by maternal education which either mitigate the negative influence or amplify the positive effect of family characteristics such as female household headship, single motherhood and polygyny. Findings from Senegal demonstrate the possibility of overcoming sociocultural barriers that family structure may pose to childhood vaccination. The progress that has been achieved with regards to child health and survival through full vaccination must be sustained as debates around the new development agenda continue to evolve. Though immunization programmes may not be able to modify family structure, they can be designed to overcome any hurdle posed by the latter. For universal coverage, immunization advocacy and awareness programmes may need to target underfive mothers who live in $\mathrm{FHHs}$ and those in polygynous families. Further research is needed on strategies to bridge the vaccination coverage gaps in countries such as Nigeria and Mali.

\section{Acknowledgements}

Our appreciation goes to the DHS program and the implementing agencies in the study countries. This research was supported by the Consortium for Advanced Research Training in Africa (CARTA). CARTA is jointly led by the African Population and Health Research Center and the University of the Witwatersrand and funded by the Wellcome Trust (UK) (Grant No: 087547/Z/08/Z), the Carnegie Corporation of New York (Grant No--B 8606.R02), Sida (Grant No:54l 00029)" The statements made and views expressed are solely the responsibility of the authors. The support of the DST-NRF Centre of Excellence in Human Development towards this research is hereby acknowledged. Opinions expressed and conclusions arrived at, are those of the author/s and are not necessarily to be attributed to the CoE in Human Development.

Authors gratefully acknowledge the support and comments from participants at the 2016 Family Demography in African and Post-2015 Development Agenda Conference, hosted by Demography and Population Studies and co-sponsored by the NRF CoE in Human Development, NRF Conference Fund and National Institute of Humanities and Social Sciences, South Africa

\section{References}

Adegboye, O. A., Kotze, D. and Adegboye, O. A. 2014. Multi-year trend analysis of childhood immunization uptake and coverage in Nigeria. J Biosoc Sci, 46, 225-39.

Adeyemi, O. A. and Oyewole, O. E. 2014. How can we really improve childcare practices in Nigeria? Health Promot Int, 29, 369-77.

Akinyemi, J. O., Chisumpa, V. H. and Odimegwu, C. O. 2016. Household structure, maternal characteristics and childhood mortality in rural sub-Saharan Africa. Rural Remote Health, 16, 3737.

Annim, S. K., Awusabo-Asare, K. and Amo-Adjei, J. 2013. Household nucleation, dependency and child health outcomes in Ghana. DHS Working Papers No. 98. Calverton, Maryland, USA: ICF International.

Antai, D. 2009. Inequitable childhood immunization uptake in Nigeria: a multilevel analysis of individual 
and contextual determinants. BMC Infect Dis, 9, 181 .

Antai, D. 2012. Gender inequities, relationship power, and childhood immunization uptake in Nigeria: a population-based cross-sectional study. Int J Infect Dis, 16, el 36-45.

Babalola, S. 2009. Determinants of the uptake of the full dose of diphtheria-pertussis-tetanus vaccines (DPT3) in Northern Nigeria: a multilevel analysis. Matern Child Health J, I3, 550-8.

Babalola, S. 20I I. Maternal reasons for nonimmunisation and partial immunisation in northern Nigeria. J Paediatr Child Health, 47, 276-8I.

Bbaale, E. 2013. Factors influencing childhood immunization in Uganda. J Health Popul Nutr, 3I, II 8-29.

Bondy, J. N., Thind, A., Koval, J. J. and Speechley, K. N. 2009. Identifying the determinants of childhood immunization in the Philippines. Vaccine, 27, 16975.

Brown, V. B. and Oluwatosin, O. A. 20I2. Sociodemographic factors associated with childhood immunization uptake in Akinyele Local Government Area, Oyo State, Nigeria. Afr J Med Med Sci, 4I, I6I-7.

Calhoun, L. M., van Eijk, A. M., Lindblade, K. A., Odhiambo, F. O., Wilson, M. L., Winterbauer, E., Slutsker, L. and Hamel, M. J. 20 I4. Determinants and coverage of vaccination in children in western Kenya from a 2003 cross-sectional survey. Am J Trop Med Hyg, 90, 234-4I.

Clouston, S., Kidman, R. and Palermo, T. 20I4. Social inequalities in vaccination uptake among children aged 0-59 months living in Madagascar: An analysis of Demographic and Health Survey data from 2008 to 2009. Vaccine, 32, 3533-3539.

Doctor, H. V. 20I I. Does living in a female-headed household lower child mortality? The case of rural Nigeria. Rural Remote Health, I I, 1635.

Ebot, J. O. 20I4. Place matters: community level effects of women's autonomy on Ethiopian children's immunization status. African Population Studies, 28, 1202-12I5.

Egondi, T., Oyolola, M., Mutua, M. K. and Elung'ata, P. 2015. Determinants of immunization inequality among urban poor children: evidence from Nairobi's informal settlements. Int J Equity Health, 14, 24.

Fatiregun, A. A. and Okoro, A. O. 20I2. Maternal determinants of complete child immunization among children aged 12-23 months in a southern district of Nigeria. Vaccine, 30, 730-6.

Gage, A. J., Sommerfelt, A. E. and Piani, A. L. 1997. Household structure and childhood immunization in Niger and Nigeria. Demography, 34, 295-309.
Gurmu, E. and Etana, E. 20I3. Household structure and children's nutritional status in Ethiopia. GENUS, 69, II 3-1 30.

Ibisomi, L. D. G. and De Wet, N. 20I4. The Dynamics of Household Structure in sub-Saharan Africa. In: Odimegwu, C. O. \& Kekovole, J. (eds.) Continuity and Change in Sub-Saharan African Demography. New York: Taylor \& Francis.

ICF International. 20I5. The DHS Program STATcompiler [Online]. Available: www.statcompiler.com [Accessed 15/08/20I5.

Kawakatsu, Y. and Honda, S. 20I2. Individual-, family- and community-level determinants of full vaccination coverage among children aged I 2-23 months in western Kenya. Vaccine, 30, 75887593.

Kumar, A. and Ram, F. 20I3. Influence of family structure on child health: Evidence from India. J Biosoc Sci, 45, 577-599.

Liu, L., Oza, S., Hogan, D., Perin, J., Rudan, I., Lawn, J. E., Cousens, S., Mathers, C. and Black, R. E. 2015. Global, regional, and national causes of child mortality in 2000-13, with projections to inform post-2015 priorities: an updated systematic analysis. Lancet, 385, 430-40.

Mackay, R. 2005. The impact of family structure and family change on child outcomes: A personal reading of the research literature. Social Policy Journal of New Zealand, 24, I I I-I 33.

Mberu, B. U. 2007. Household structure and living conditions in Nigeria. Journal of Marriage and Family, 69, 5 I 3-527.

Mukungwa, T. 2015. Factors Associated with full Immunization Coverage amongst children aged 12-23 months in Zimbabwe. African Population Studies, 29, I76I-I774.

Odusanya, O. O., Alufohai, E. F., Meurice, F. P. and Ahonkhai, V. I. 2008. Determinants of vaccination coverage in rural Nigeria. BMC Public Health, 8 , 381.

Omariba, D. W. R. and Boyle, M. H. 2007. Familiy structure and child mortality in sub-Saharan Africa: Cross-National effects of polygyny. Journal of Marriage and Family, 69, 528-543.

Onsomu, E. O., Abuya, B. A., Okech, I. N., Moore, D. and Collins-McNeil, J. 20I5. Maternal Education and Immunization Status Among Children in Kenya. Matern Child Health J, 19, I724-33.

Rossi, R. 2015. Do Maternal Living Arrangements Influence the Vaccination Status of Children Age 12-23 Months? A Data Analysis of Demographic Health Surveys 20 I0-II from Zimbabwe. PLoS One, 10, e0132357.

Rutstein, S. O. 2008. The DHS wealth index: Approaches for rural and urban areas. DHS 
Working Papers No. 60. Calverton, Maryland, USA: Macro International.

Scott, M. E., Wilcox, W. B., Ryberg, R. and DeRose, L. 20I5. Mapping family change and child wellbeing outcomes. World Family Map. New York: Social Trends Institute.

Singh, K., Bloom, S. and Brodish, P. 2015. Gender equality as a means to improve maternal and child health in Africa. Health Care Women Int, 36, 5769.

Singh, K., Haney, E. and Olorunsaiye, C. 2013. Maternal autonomy and attitudes towards gender norms: associations with childhood immunization in Nigeria. Matern Child Health J, I7, 837-4I.

Tarantola, D., Hacen, M., Lwanga, S. and Clements, C. J. 2014. Is immunisation coverage in Africa slipping? An evaluation of regional progress to 2013. Annals of Vaccines and Immunization, I.

The DHS Program. 2015. Available Datasets

[Online]. Available:

https://dhsprogram.com/data/availabledatasets.cfm [Accessed 10 August 20I5].

Tobin-West, C. I. and Alex-Hart, B. A. 201 I. Identifying barriers and sustainable solution to childhood immunization in Khana local government area of Rivers State, Nigeria. Int Q Community Health Educ, 32, 149-58.

Tsawe, M., Moto, A., Netshivhera, T., Ralesego, L., Nyathi, C. and Susuman, A. S. 2015. Factors influencing the use of maternal healthcare services and childhood immunization in Swaziland. Int J Equity Health, 14, 32.
UNICEF 2015. Levels and trends in child mortality: Estimates developed by the UN Inter-agency Group for Child Mortality Estimation (IGME). New York: UNICEF.

United Nations 2015. The Millennium Development Goals Report. New York

Vikram, K., Vanneman, R. and Desai, S. 2012. Linkages between maternal education and childhood immunization in India. Social Science \& Medicine, 75, 331-339.

Westoff, C. F. 2003. Trends in marriage and early childbearing in developing countries. DHS Comparative Reports No. 5. Calverton, Maryland, USA: ORC Macro.

WHO. 20I5a. Country Profiles, Data and Statistics on Immunization [Online]. WHO. Available: http://www.who.int/immunization/monitoring_sur veillance/en/ [Accessed 2I Sept 2015.

WHO. 20I5b. WHO recommendations for routine immunization - summary tables [Online].

Available: http://www.who.int/immunization/policy/immuniz ation_tables/en/ [Accessed 21/09/20I5].

WHO and UNICEF. 20I4. Immunisation coverage estimates 2013 revision [Online]. WHO/UNICEF. Available:

http://apps.who.int/immunization_monitoring/glob alsummary/timeseries/tswucoveragebcg.html. [Accessed 21/09/2015].

Zuehlke, E. 2009. Child Mortality Decreases Globally and Immunization Coverage Increases, Despite Unequal Access. Washington, DC 20009:

Population Reference Bureau. 